Jahangirnagar University J. Biol. Sci. 7(1): 15-21, 2018 (June)

\title{
Effects of different supplementary feeds on the growth performance and survival of Labeo bata fry
}

\author{
Md. Baki Billah ${ }^{*}$, Suny Akter, Suraiya parveen ${ }^{1}$, Azizur Rahman², Lutfun Nahar ${ }^{3}$ \\ and Md. Kamrujjaman \\ Department of Zoology, Jahangirnagar University, Savar, Dhaka-1342, Bangladesh
}

\begin{abstract}
An experiment was conducted with Labeo bata fry for 60 days to examine the growth performance and survival in response to three supplementary feeds i.e. wheat bran, maize bran and mixed diet. The length gain, percent length gain, weight gain, percent weight gain and specific growth of the fry were found significantly higher $(\mathrm{p}<0.05)$ in mixed diet. The highest survival rate $(74.38 \pm 8.1 \%$ ) was shown by the mixed diet treated fry which was significantly higher than those of maize bran and wheat bran treated fry respectively. There were no significant differences $(\mathrm{p}<0.05)$ among the treatments in term of water temperatures, $\mathrm{pH}$ and dissolved oxygen (DO). Thus, on the basis of the fry growth performance and survival rate, it could be suggested that the mixed diet of wheat bran and maize bran is suitable for the culture of L. bata fry.
\end{abstract}

Key words: Labeo bata, fry, maize bran, wheat bran, growth.

\section{INTRODUCTION}

Bangladesh is one of the world's leading fish producing countries. The availability of fish fry is an essential prerequisite for fish culture (Moniruzzaman \& Mollah, 2010). Nowadays, due to the degradation of fish habitat and increase in aquatic pollution the natural resources of fish fry are being destroyed. So, hatcheries are now the main sources of fish fry supply. Bangladesh is facing tremendous problem of fry production and rearing due to the lack of technical knowledge and proper management practices. For improved fish culture, it is therefore imperative to know how feeds are related to growth and survival of fry (Moniruzzaman \& Mollah, 2010) in laboratory condition.

Labeo bata inhabits rivers, haors, baors, beels, canals and ponds of Bangladesh (Mahfuj et al., 2012b). L. bata has faster growth rate, higher market value, deliciousness and easy culture system using supplemental feeds making it popular fish to adopt in culture by medium scale fish farmers (Suraiya et al., 2009). They eat protozoa, algae, and tiny fishes. Many commercial fish feeds viz. Saudi-Bangla Nursery Feed (Saudi-Bangla Fish Feed Bangladesh Ltd.), Quality Nursery Feed (Quality Fish Feed Bangladesh Ltd.) and Aftab Nursery Feed (Aftab Feed Bangladesh Ltd.) are commonly used for mass

${ }^{1}$ Research Fellow, Biological Research Division, Zoology Section, BCSIR

${ }^{2}$ Department of Statistics, Jahangirnagar University, Savar, Dhaka-1342, Bangladesh

${ }^{3}$ Department of Chemistry, Jahangirnagar University, Savar, Dhaka-1342, Bangladesh

*Corresponding author. Email: bakibillah29@juniv.edu 
production of L. bata seeds. Among these, Saudi-Bangla nursery feed for carps and catfishes has become popular because of its high protein content (30\%) and also fish can take it easily due to its high compactness (Ahammad et al., 2009). With the growing demand for fish, the use of aquaculture feed in Bangladesh has grown substantially. It seems that commercial pelleted feeds are beginning to replace farm-made and raw unformulated feeds. At present there are at least 25 commercial fish feed mills in Bangladesh. But the total fish feed pellet production is not sufficient to fulfill the increasing demand for fish feed. Therefore, there are great demands for million tonnes of locally-formulated and processed fish feed pellet in Bangladesh. Nutritionally deficient diets can lead to poor growth and induce disease conditions which ultimately leading to death while adequate and appropriate diets can lead to successful aquaculture (Mollah et al., 2009).

Protein is the basic component of animal tissues, and is therefore, an essential nutrient for both maintenance and growth. The requirements for protein in larval fish are greater than in adult fish and the requirement for essential fatty acids are also greater (Mahfuj et al., 2012a). Fish farmers of the country are using high protein content artificial feed for the nursery rearing of this species in their nursery ponds which is not cost effective. So, suitable feed for nursery rearing needs to be identified and finally ensured. Therefore, in this study supplementary feeds such as wheat bran, maize bran and mixed diet of wheat bran, maize bran were used to study the growth and survival of $L$. bata in successful aquaculture. This study will be helpful to the hatchery owners, fish culturists and extension workers to run a hatchery effectively as well as to improve the quality fish seed and fry production in a cost effective way.

\section{MATERIALS AND METHODS}

Fish collection and conditioning: The experiment was conducted for two months starting from first of April to the end of May 2017 in the laboratory of Fish Hatchery and Research Centre, Jahangirnagar University, Bangladesh. Healthy, mature L. bata was collected from Jahangirnagar University campus hatchery pond prior to 4 hours of induced breeding.

Induced breeding: The induced breeding of $L$. bata was carried out as previously described (Miah et al., 2008; Hossain et al., 2007). Briefly, the females were first injected at the rate of $1.0 \mathrm{mg} \mathrm{PG} / \mathrm{kg}$ body wt. while the second doses were performed at the rate of $5.0 \mathrm{mg} \mathrm{PG} / \mathrm{kg}$ body wt. after $6 \mathrm{~h}$ from the first dose. On the other hand, the males were administered a single dose of $2 \mathrm{mg} P \mathrm{PG} / \mathrm{kg}$ body wt. at the time of second dose of the female. The male and female fishes were kept in a circular tank for natural spawning. After 8 hours the fertilized eggs were collected and the hatchings were reared in a hapa for 7 days.

Preparation of feeds: About two-third water from each aquarium was replaced with deep tube well water at each alternate day. The faecal matter and wastage of food were removed by siphoning. Proper aeration was provided and was stopped during feeding. 
The proximate composition of wheat bran, maize bran and mixed diet (50\% wheat bran + $50 \%$ maize bran) were analyzed following the standard methods given by Association of Official Analytical Chemists (AOAC, 1980). The fish were fed with extruded fish feeds at $3 \%$ of the fish body weight.

Experimental design: The experiment was designed as described previously with slight modification (Ahammad et al., 2009; Moniruzzaman \& Mollah, 2010 and Mahfuj et al., 2012a).

Stocking: The 15 days old fry (average length $3.62 \pm 0.9 \mathrm{~mm}$ and weight $0.008 \mathrm{~g}$ ) were taken in glass aquaria and fed with different artificial feeds to examine the growth performance in response to different diets. The experiment was conducted in nine rectangular glass aquaria $(47 \times 26 \times 24 \mathrm{~cm})$ each containing $50 \mathrm{~L}$ of deep tube well water. The experiment was designed with 3 treatments $\left(T_{1}, T_{2}\right.$ and $\left.T_{3}\right)$ each having 2 replications. The fry were released in the aquarium at the density of 4 fry $/ \mathrm{L}$ of water i.e. 200 fry in each aquarium and reared for 60 days as described previously (Ahammad et al., 2009; Moniruzzaman \& Mollah, 2010).

Sampling procedure: The fish were sampled at weekly interval to determine the increase in length and weight. Sampling of fish was done early in the morning when the stomach of the fish was almost empty to avoid the biasness of fish weight due to intake of food. Fifteen (15) fry were randomly collected to take length and weight data. Weight was taken by digital analytical balance and length was measured placing the fish on $1 \mathrm{~mm}$ graph paper

Water quality parameters: During the study period the physico-chemical parameters i.e., temperature, $\mathrm{pH}, \mathrm{DO}$ and transparency of both fry rearing tank and aquarium were investigated with the help of aqua mate water testing kit (Model WAKQ-1A). All analysis was done in the fish hatchery and research centre in Jahangirnagar University.

Growth parameters: For determining the growth parameters, the following formulae were used as described by Mahfuj et al., 2012b.

1) Length gain of fry $(\mathrm{mm})=$ Average final length of fry - average initial length of fry.

2) Weight gain of fry $(\mathrm{g})=$ Average final weight of fry - average initial weight of fry.

3) Percent gain in length= Average final length-average initial length)/ Average initial length $\times 100$

4) Percent gain in weight $=($ Average final weight-average initial weight $) /$ Average initial weight $\times 100$

5) Specific Growth Rate $(\mathrm{SGR})=\left(\ln _{\mathrm{f}}-\ln \mathrm{W}_{\mathrm{ix} 100}\right) / \mathrm{t}$

$\operatorname{lnW}_{\mathrm{f}}=$ the natural logarithm of the final weight, $\ln \mathrm{W}_{\mathrm{i}}=$ the natural logarithm of the initial weight, $\mathrm{t}=$ time (days) between $\ln \mathrm{W}_{\mathrm{f}}$ and $\ln \mathrm{W}_{\mathrm{i}}$

6) The survival rate $=($ No. of fry alive/Total number of stocked) $\mathrm{X} 100$ 
Statistical analysis: All the growth parameters were tested using one-way analysis of variance (ANOVA). Significant results $(\mathrm{p}<0.05)$ were further tested using Duncan's Multiple Range Test (DMRT) with the aid of the computer software SPSS 17.0 program.

\section{RESULTS AND DISCUSSION}

Water Quality Parameters: During the experimental period the measured water quality parameters were given in Table-1. In this experiment, the water temperature was maintained at $28^{\circ} \mathrm{C}, 29^{\circ} \mathrm{C}, 28^{\circ} \mathrm{C}$ and $32^{\circ} \mathrm{C}$ in $\mathrm{T}_{1}, \mathrm{~T}_{2}, \mathrm{~T}_{3}$ and nursery rearing pond respectively. No significant differences in mean water temperatures were recorded among the treatments $(\mathrm{p}>0.05)$. The water temperatures recorded during the study period in both experiments were within the suitable range for fish culture (DOF, 2010). Hossain et al., (2007) also reported similar temperature ranges during nursery practices of L. bata. But, the ranges of $\mathrm{pH}$ were 7 in $\mathrm{T}_{1}, \mathrm{~T}_{2}, \mathrm{~T}_{3}$ and nursery rearing pond respectively. $\mathrm{pH}$ value was not found significant among the treatments throughout the study period. In addition, the dissolved oxygen ranged $5 \mathrm{mg} / \mathrm{L}$ in $\mathrm{T}_{1}, 5 \mathrm{mg} / \mathrm{L}$ in $\mathrm{T}_{2}, 5 \mathrm{mg} / \mathrm{L}$ in $\mathrm{T}_{3}$ and $45 \mathrm{mg} / \mathrm{L}$ in nursery rearing pond. The average dissolved oxygen was within the normal range as recommended by (DOF, 2010).

Table 1. Mean $( \pm$ SD) water quality parameters recorded in nursery pond and glass tank aquariums

\begin{tabular}{l|c|c|c|c|c}
\hline Parameters & $\begin{array}{c}\text { Wheat bran } \\
\left(\mathrm{T}_{1}\right)\end{array}$ & $\begin{array}{c}\text { Maize bran } \\
\left(\mathrm{T}_{2}\right)\end{array}$ & Mixed diet $\left(\mathrm{T}_{3}\right)$ & $\begin{array}{l}\text { Nursery } \\
\text { pond }\end{array}$ & $\begin{array}{l}\text { Level of } \\
\text { significance }\end{array}$ \\
\hline Temperature & $28 \pm 0.36$ & $29 \pm 0.14$ & $28 \pm 0.29$ & $32 \pm 0.16$ & $\mathrm{NS}$ \\
$\mathrm{pH}$ & $7 \pm 0.48$ & $7 \pm 0.62$ & $7 \pm 0.52$ & $7 \pm 0.41$ & $\mathrm{NS}$ \\
DO $(\mathrm{mg} / \mathrm{L})$ & $5 \pm 0.11$ & $5 \pm 0.61$ & $5 \pm 0.32$ & $4 \pm 0.17$ & $\mathrm{NS}$ \\
\hline
\end{tabular}

NS indicates non-significant at $0.05 \%$ level

Growth performance of $\boldsymbol{L}$. bata: The experiment was conducted for 60 days in order to observe the effects of different supplementary feeds on the growth and survival of the fry of L. bata. Proximate composition of feeds were analyzed and given in Table 2. The initial average lengths of the fry were $3.62 \pm 0.41,3.60 \pm 0.13$ and $3.59 \pm 0.52 \mathrm{~mm}$ for treatments $\mathrm{T}_{1}$ (wheat bran), $\mathrm{T}_{2}$ (maize bran) and $\mathrm{T}_{3}$ (mixed diet) respectively, whereas, the initial weight for treatments $\mathrm{T}_{1}, \mathrm{~T}_{2}$ and $\mathrm{T}_{3}$ were $0.008 \pm 0.11,0.005 \pm 0.51$ and $0.006 \pm 0.29 \mathrm{~g}$ respectively (Table 3).

The highest length gain was found to be $31.81 \pm 3.75 \mathrm{~mm}$ in treatment $\mathrm{T}_{3}$ which is significantly $(\mathrm{p}<0.05)$ higher than that of $\mathrm{T}_{1}$ and $\mathrm{T}_{2}$. Similarly, the highest gain in weights of the fry was $0.504 \pm 0.11 \mathrm{~g}$ in treatment $\mathrm{T}_{3}$ which is significantly $(\mathrm{p}<0.05)$ higher than those of $T_{1}$ and $T_{2}$ treatments. The highest percent length gain was $886.07 \pm 9.1 \%$ and percent weight gain was $8400 \pm 18.12 \%$ as observed in treatment $\mathrm{T}_{3}$ where the fry were fed with mixed diet (Table 3). At the end of the experiment, the highest specific growth rate and survival rates were found to be $3.2 \pm 0.06$ and $74.38 \pm 8.10 \%$ in case of $\mathrm{T}_{3}$ treatment 
which was significantly $(\mathrm{p}<0.05)$ higher compared to those in treatment $\mathrm{T}_{1}$ and $\mathrm{T}_{2}$ (Table 3 ). Outcomes of the experiment showed better performance of mixed diet over the treatment performance of wheat bran and maize bran alone in case of $L$. bata fry culture.

Table 2. Proximate composition of feeds (after 60 days) used for rearing of $L$. bata fry

\begin{tabular}{l|c|c|c|c}
\hline Feeds & Protein (\%) & Lipid (\%) & Moisture (\%) & Others (\%) \\
\hline Wheat bran & 19.10 & 8.97 & 12.57 & 59.36 \\
Maize bran & 17.34 & 10.53 & 11.21 & 60.92 \\
Mixed diet & 22.41 & 9.71 & 9.56 & 58.32 \\
\hline
\end{tabular}

Table 3. Growth performance of $L$. bata fry (after 60 days) exposed to different feeds

\begin{tabular}{lcc|c}
\hline Parameters & $\begin{array}{c}\text { Wheat bran } \\
\left(\mathrm{T}_{1}\right)\end{array}$ & $\begin{array}{c}\text { Maize bran } \\
\left(\mathrm{T}_{2}\right)\end{array}$ & Mixed diet $\left(\mathrm{T}_{3}\right)$ \\
\hline Initial length $(\mathrm{mm})$ & $3.62 \pm 0.41$ & $3.60 \pm 0.13$ & $3.59 \pm 0.52$ \\
Final length $(\mathrm{mm})$ & $23.12 \pm 1.05^{\mathrm{a}}$ & $27.5 \pm 1.061^{\mathrm{b}}$ & $35.4 \pm 1.03^{\mathrm{c}}$ \\
Length gain $(\mathrm{mm})$ & $19.5 \pm 1.25^{\mathrm{a}}$ & $23.9 \pm 2.13^{\mathrm{b}}$ & $31.81 \pm 3.75^{\mathrm{c}}$ \\
Percent length gain & $538.67 \pm 6.1^{\mathrm{a}}$ & $663.88 \pm 7.2^{\mathrm{b}}$ & $886.07 \pm 9.1^{\mathrm{c}}$ \\
Initial weight $(\mathrm{g})$ & $0.008 \pm 0.11$ & $0.005 \pm 0.51$ & $0.006 \pm 0.29$ \\
Final weight $(\mathrm{g})$ & $0.22 \pm 0.03^{\mathrm{a}}$ & $0.36 \pm 0.08^{\mathrm{b}}$ & $0.51 \pm 0.01^{\mathrm{c}}$ \\
Weight gain $(\mathrm{g})$ & $0.212 \pm 0.04^{\mathrm{a}}$ & $0.355 \pm 0.08^{\mathrm{b}}$ & $0.504 \pm 0.11^{\mathrm{c}}$ \\
Percent weight gain & $2650 \pm 11.01^{\mathrm{a}}$ & $7100 \pm 14.24^{\mathrm{b}}$ & $8400 \pm 18.12^{\mathrm{c}}$ \\
Specific growth rate & $2.3 \pm 0.03^{\mathrm{a}}$ & $3.0 \pm 0.01^{\mathrm{b}}$ & $3.2 \pm 0.06^{\mathrm{c}}$ \\
\hline \multicolumn{1}{c}{ Survival } & $54.21 \pm 6.13^{\mathrm{a}}$ & $69.12 \pm 4.76^{\mathrm{b}}$ & $74.38 \pm 8.10^{\mathrm{c}}$ \\
\hline
\end{tabular}

Values with different superscripts in a row are significantly different (one way ANOVA followed by Duncan test, $\mathrm{p}<0.05)$.

Hossain et al. (2007) conducted experiment to observe the breeding performance and nursery practices of the threatened indigenous fish species, Labeo bata in Jessore, Bangladesh during 1998 to 2002. In this study, they found the highest length $(19.37 \mathrm{~mm})$, weight $(57.67 \mathrm{mg})$ and survivability $(63.33 \%)$ when used rice bran and mustard oil cake together at rate $30 \mathrm{~g} /$ day. Similarly, in our study we obtained the highest length, weight and survivability when L. bata fry were fed with mixed diet $(50 \%$ wheat bran $+50 \%$ maize bran) for 60 days. In an another study (Selvaraj et al., 1972), L. boggut spawn were fed with zooplanktonic food for 10 days and the total length was obtained $16.993 \mathrm{~mm}$ which was almost similar when rice bran was used (Hossain et al., 2007). This suggests that the growth and survival rate of carp hatchlings depend largely on the easy availability of planktonic food organisms in general.

Hecht \& Appelbaum (1988) conducted an experiment with the fry and juveniles of Clarias gariepinus and found that growth and survival was density dependent and live food was preferred to formulate feed. In this experiment, the stocking density was 30 fry in each aquarium but in our experiment we took 200 fry in each aquarium as described earlier (Ahammad et al., 2009; Maniruzzaman \& Mollah 2010). 
Another study reported that the growth performance and survival of fry and fry of Clarias macrocephalus were directly influenced by feeding frequency (Mollah \& Tan, 1983). They explained that three times feeding frequency was best for rearing the fry and fry of Clarias macrocephalus. In our experiment, we fed the fry two times daily.

Debnath \& Brugge (2005) conducted an experiment and found that in early stage of the life cycle of common carp the survival rate was very poor. In their study, pellet feed was used but the survival rate was lower because pellet food deteriorated the water quality much than that of other feeds. The reason might be the poor physiological development of earlier stage. In our experiment, the water quality parameters were within the range of fish culture and mixed diet yielded better growth performances over the treatment performance of wheat bran and maize bran alone.

The water temperatures, $\mathrm{pH}$ and dissolved oxygen recorded in this study were within the suitable range for fish culture. The highest length gain, percent length gain, weight gain and percent weight gain of the fry was found in mixed diet $(50 \%$ wheat bran $+50 \%$ maize bran) which was significantly higher than those of wheat bran and maize bran treatments alone. The highest specific growth rate and survival rates were found 3.2 \pm 0.06 and $74.38 \pm 8.10 \%$ in case of fry fed with mixed diet. Therefore, depending on growth performance mixed diet $(50 \%$ wheat bran $+50 \%$ maize bran) for fry rearing of L. bata could be recommended. The results of the present study clearly demonstrated that the use of low cost supplemental mixed feed $(50 \%$ wheat bran $+50 \%$ maize bran) has significant role in promoting the growth of L.bata fry.

\section{REFERENCES}

Ahammad, A. K. S., Khan, M. M. R., Hossain, M. A. and Parvez, I. 2009. Nurseries rearing of Thai sarpunti, Barbonymus gonionotus fry using three different supplementary feeds. Journal of the Bangladesh Agricultural University, 7(1), 139-144.

AOAC (Association of Official Analytical Chemists). 1980. Official methods of analysis of Association of Official Analytical Chemists (ed. W. Hoewitz), 13th edition Washington, D.C. p. 78.

Debnath, J. and Brugge, J. S. 2005. Modelling glandular epithelial cancers in three-dimensional cultures. Nature Reviews Cancer, 5(9), 675-688.

DOF. 2010. "Fisheries Statistical Year Book of Bangladesh 2008-2009”. Volume 26, No. 1. Fisheries Resource Survey System, Department of Fisheries, Ministry of Fisheries and Livestock.

Hecht, T. and Appelbaum, S. 1988. Observations on intraspecific aggression and coeval sibling cannibalism by larval and juvenile Claias gariepinus (Clariidae: Pisces) under controlled conditions. Journal of Zoology, 214(1), 21-44.

Hossain, Q. Z., Hossain, M. A. and Parween, S. 2007. Breeding Performance and Nursery Practices of Labeo bata (Hamilton-Buchanan, 1822). Scientific World, 5(5), 40-45.

Mahfuj, M. S., Hossain, M. A. and Sarower, M. G. 2012a. Effect of different feeds on larval development and survival of ornamental koi carp, Cyprinus carpio (Linnaeus, 1758) fry in laboratory condition. Journal of the Bangladesh Agricultural University, 10(1), 179183. 
Mahfuj, M.S., Hossain, M.B. and Minar, M.H. 2012b. Biochemical Composition of an Endangered Fish, Labeo bata (Hamilton, 1822) from Bangladesh Waters. American Journal of Food Technology, 7. 633-641.

Miah, M. I., Mamun, A. A., Khan, M. M. R. and Rahman, M. M. 2008. Dose optimization with pituitary gland hormone for induced breeding of bata fish (Labeo bata). Bangladesh Journal of Animal Science, 37(1), 70-77.

Mollah, M. F. A. and Tan, E. S. P. 1983. HCG-induced spawning of the catfish, Clarias macrocephalus (Gunther). Aquaculture, 35, 239-247.

Mollah, M.F.A., Mamum, M.S.A., Sarowar, M.N. and Roy, A. 2009. Effect of stocking density on growth and breeding performance of brood fish and larval growth and survival of shol, Channa striatus (Bloch). Journal of Bangladesh Agriculture University, 7(2). 427-432.

Moniruzzaman, M. and Mollah, M. F. A. 2010. Effects of rice bran on growth and survival of Thai sharpunti Barbodes gonionotus in earthen ponds. Journal of the Bangladesh Agricultural University, 8(1), 161-171.

Selvaraj, C., Radhakrishnan, S. and Parameswaran, S. 1972. Notes on the breeding season, fecundity and life-history of a minor carp, Labeo boggut (Sykes). Journal of the Inland Fisheries Society of India, IV: 87-97.

Suraiya, S., Khan, M.M.R, Haq, M., Hossain, M.A. and Ahammad, A.K.S. 2009. Morphological and allozyme variation of three river populations of bata, Labeo bata (Hamilton) in Bangladesh. International Journal of Bio-Research, 6(3). 6-13. 